\title{
Laparoscopic management of adnexal torsion
}

\author{
Meena A Khatri ${ }^{1}$ \\ Sri Lanka Journal of Obstetrics and Gynaecology 2011; 33: 56-59
}

\begin{abstract}
Objective: Torsion of the uterine adnexa accounts for approximately $2.7 \%$ of all gynaecological emergencies [Mancuso et al, 1997] and also a rare but important cause of acute abdominal pain ${ }^{1}$. The purpose of present study is to determine if detorsion of the twisted ovarian cyst is better than traditional salpingooopherectomy and evaluate the outcome of minimally invasive laproscopic surgery in the management of adnexal masses.
\end{abstract}

Method: A prospective study included all the patients with twisted adnexa from January 2008 to November 2010 at Acharya Vinoba Bhave Rural Hospital, Datta Meghe Institute of Medical Sciences University, Sawangi (Meghe), Wardha, India.

Results: A total of 24 patients with twisted adnexa underwent laparoscopic surgery. In the present study successful detortion and conservation of adnexa could be achieved in $19(82 \%)$ patients. There was one conversion to laparotomy.

Conclusions: Present study proved that timely diagnosis and intervention could help the ovarian salvage in women of reproductive age group. Prognosis was excellent with early diagnosis and appropriate management.

Keywords: twisted adnexa, detortion, laparoscopy, ultrasound colour Doppler.

\section{Introduction}

Adnexal torsion is an infrequent but significant cause of acute lower abdominal pain in women. The clinical presentation is often nonspecific with few distinctive physical findings commonly resulting in delayed diagnosis and surgical management ${ }^{2}$.

\footnotetext{
${ }^{1}$ Department of Obstetrics and Gynaecology, Datta Meghe Institute of Medical Sciences University, Sawangi (Meghe), Wardha, India.

Correspondence: Meena A Khatri

E-mail: meenakhatri619@yahoo.com
}

Imaging diagnosis is mostly performed by two dimensional ultrasonography in gray-scale or associated colour Power Doppler ${ }^{4}$. If not diagnosed and treated, this condition might lead to necrosis, loss of ovary and infertility ${ }^{5}$. Until two decades ago, the standard approach to twisted adnexa was salpingooopherectomy. In 1989, Mage et al proved that detorsion and preservation of adnexa is an alternative mode of treatment ${ }^{3}$. Timely diagnosis and management can help ovarian salvage in women of reproductive age group. In recent years minimally invasive laparoscopic surgery has changed the therapeutic management of adnexal masses to such an extent that it can be considered the standard therapeutic option.

\section{Methods}

A prospective study was conducted in the Department of Obstetrics and Gynaecology, Datta Meghe Institute of Medical Sciences University, Sawangi (Meghe), Wardha, India from January 2008 to November 2010. Twenty four patients with twisted adnexa, diagnosed by clinical examination, ultrasonography and colour Doppler were included in the study. The patients with twisted adnexa presented with acute onset of severe unilateral abdominal or pelvic pain, coliky in nature and more so on right side in majority of the patients. However, some patients presented with nausea, vomiting and fever. Physical examination revealed lower quadrant tenderness of abdomen and bimanual pelvic examination demonstrated uterine shift towards the affected side and a palpable mass on one side and adnexal tenderness in $60 \%$ of women. Immediate ultrasound with colour Doppler was performed to diagnose by demonstration of a cystic mass with or without pelvic fluid and thickening of the wall and cystic haemorrhage. Diagnosis was confirmed by demonstration of abnormal flow on colour Doppler.

\section{Results}

Present study was conducted from January 2008 to November 2010. Total 24 patients diagnosed with adnexal torsion. Twenty three were non-pregnant and one patient with 8 weeks pregnancy with twisted ovarian cyst. Most patients were in the age group 2029 years (Table 1 ). Most common symptom was acute lower abdominal pain, nausea and fever. Out of twenty four patients with twisted adnexa, 21 patients 
were with ovarian cyst, two patients with paraovarian cyst and one patient with twisted hydrosalpinx.

Detwisting of adnexa with conservation of ovaries could be achieved in 18 patients $(75 \%)$ and adnexectomy done in 5 (20.83\%), 2 for Dermoid cyst, 2 for paraovarian cyst and 1 patient with borderline serous-cystadenocarcinoma (frozen section) removed by laparotomy. One patient with twisted hydrosalpinx detorsion followed by aspiration of hydrosalpinx and delinking of tube done in order to preserve the blood flow to the ovarian tissue on same side. All the eighteen patients with ovarian conservation were followed with ultrasound and colour Doppler, almost $89 \%$ of patients showed ovarian preservation in the form of follicular development and ovulation and normal blood flow on colour Doppler.

Table 1. Age distribution of women

\begin{tabular}{lcc}
\hline $\begin{array}{l}\text { Age group } \\
\text { (yrs) }\end{array}$ & $\begin{array}{c}\text { No. of } \\
\text { women }\end{array}$ & $\begin{array}{c}\text { Percentage } \\
(\%)\end{array}$ \\
\hline $10-19$ & 4 & 16.67 \\
$20-29$ & 16 & 66.67 \\
$30-39$ & 4 & 16.67 \\
Total & 24 & 100.00 \\
\hline
\end{tabular}

Table 2. Detorsion of twisted adnexa and subsequent ovarian function: a review of literature

\begin{tabular}{lccccc}
\hline Study & $\begin{array}{c}\text { No. of } \\
\text { patients }\end{array}$ & Laparoscopy & Laparotomy & $\begin{array}{c}\text { Subsequent } \\
\text { ovarian function }\end{array}$ & $\%$ \\
\hline Mage et al 1989 & 27 & 22 & 5 & $16 / 17$ & 94 \\
Gabriel et al 2003 & 102 & 67 & 35 & $85 / 92$ & 91 \\
Out study 2008-10 & 24 & 23 & 1 & $16 / 18$ & 89 \\
\hline
\end{tabular}

Table 3. Histology of cyst excised at detorsion

\begin{tabular}{lcc}
\hline Type of cyst & No. of women & Percentage (\%) \\
\hline PCOS & 2 & 10.53 \\
Follicular & 5 & 26.32 \\
Hydrosalpinx & 1 & 5.26 \\
Simple serous cystadenoma & 11 & 57.89 \\
Total & 19 & 100.00 \\
\hline
\end{tabular}

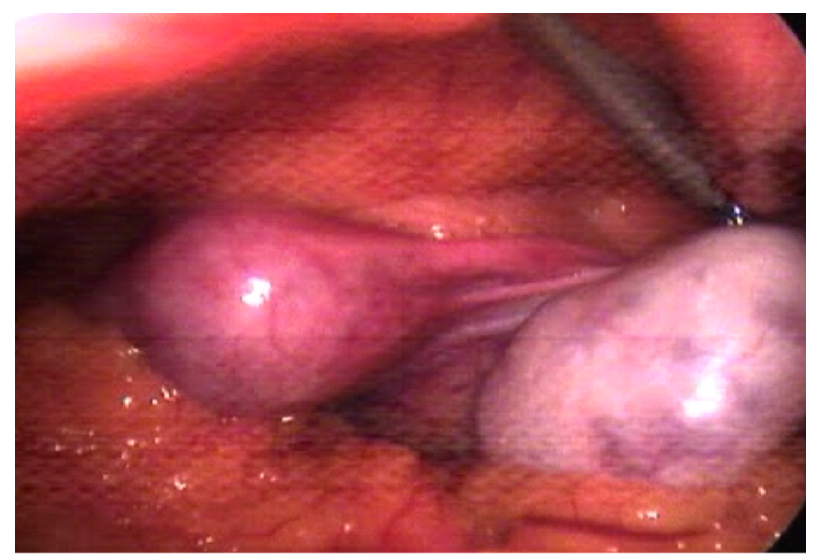

Twisted polycystic ovary on right side

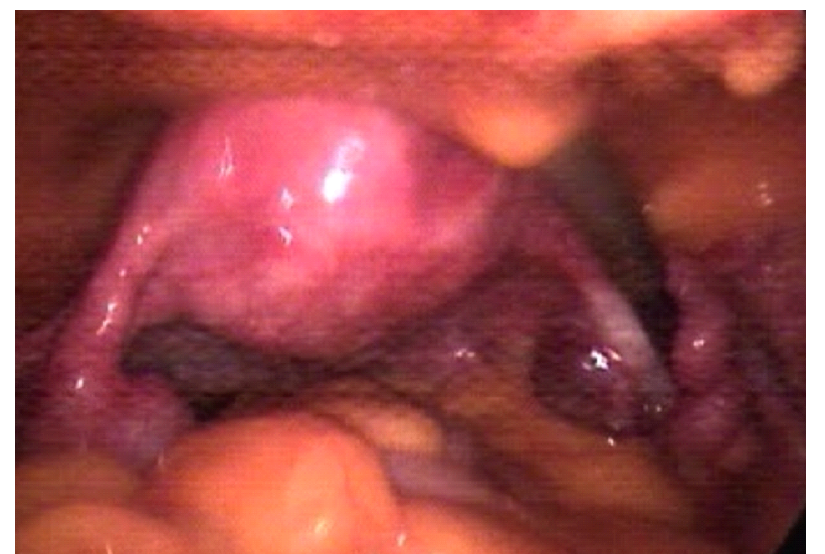

Twisted hydrosalpinx with ovarian adhesions 


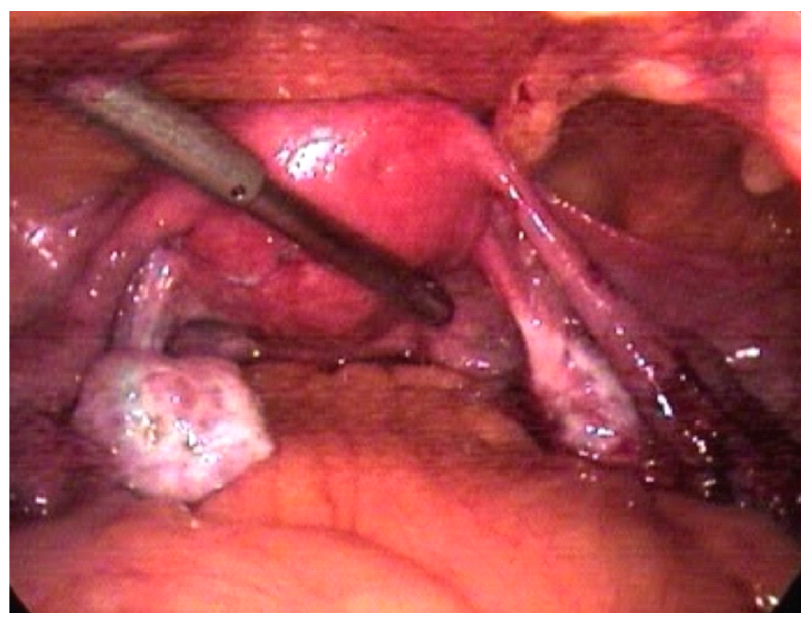

Normal appearance of tubes and ovaries at the end of procedure

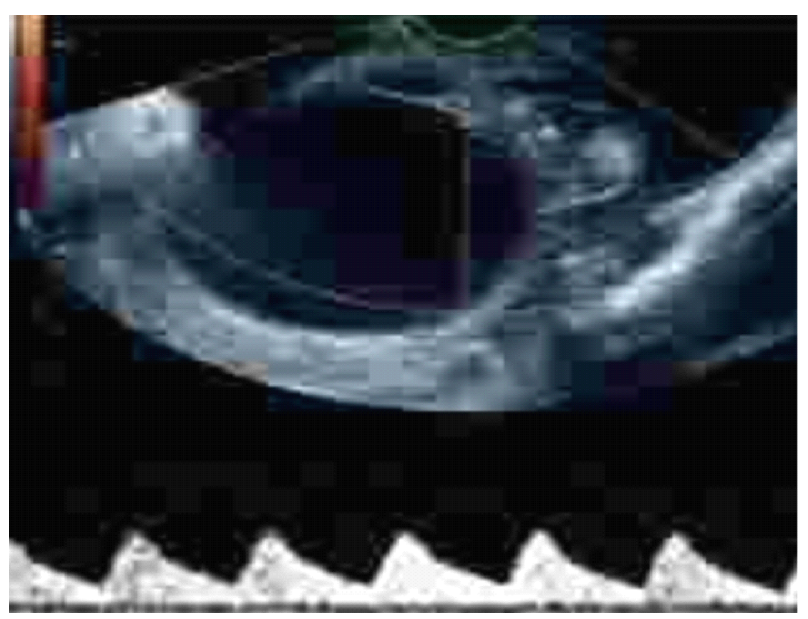

Doppler of twisted ovarian cyst

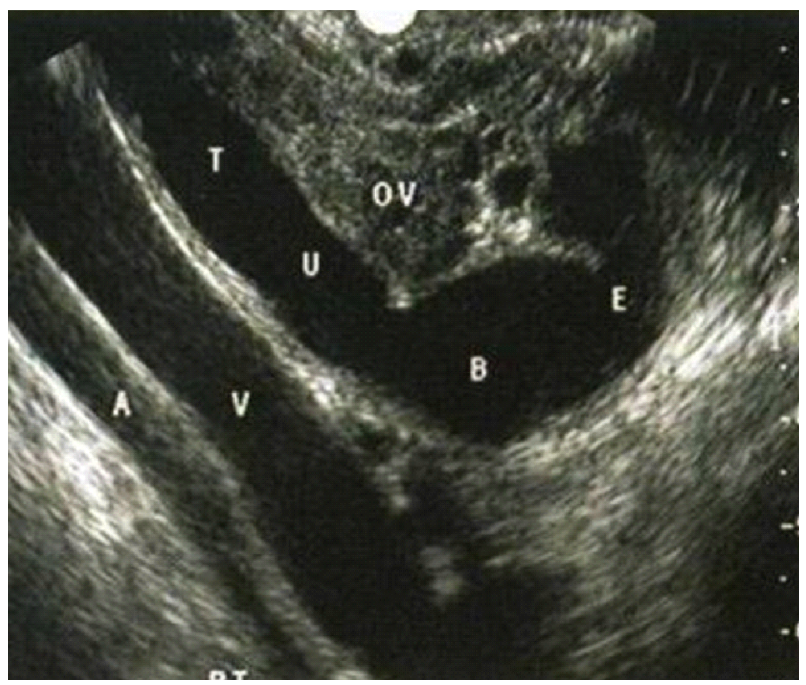

Hydrosalpinx

\section{Discussion}

Ovarian torsion can affect women of all ages, although it is more frequent in women during their reproductive age $(70.6 \% \text { between } 20 \text { and } 39 \text { years old })^{5}$. This higher incidence is due to increased adnexal mobility in young women ${ }^{7}$. Ovulation induction, ovarian enlargement and pregnancy are most common predisposing factors for ovarian torsion. Ovarian enlargement of any etiology predisposes the adnexa to torsion. However, normal ovaries undergo torsion especially in pre-puberscent-females ${ }^{8}$. Clinically ovarian torsion present with non specific symptoms that include nausea, vomiting and lower abdominal pain. The torsion can be complete, leading to haemorrhagic necrosis and loss of the ovary ${ }^{9}$. It can also be insidious leading to a large ovarian oedema due to the increase in capillary hydrostatic pressure ${ }^{10}$. Imaging diagnosis is mostly performed by two dimensional ultrasonography (2DUS) grayscale, associated to power and colour Doppler. The main findings of 2DUS grayscale is the enlarged volume of the ovary with central heterogenous stroma and multiple small follicles along its periphery measuring less than $5 \mathrm{~mm}^{11}$. On average 2DUS in colour Doppler can provide important information about ovarian flow and vascularization, and it is very important to establish ovarian viability, in case of torsion ${ }^{12}$ before surgery. However, the evaluation of a twisted ovary through 2DUS in colour Doppler is limited, since it cannot quantify the vascularization of all ovarian tissue. 3D Power Doppler might greatly help the quantitative vascular assessment of the ovary and selection of patients with ovarian torsion and the definition about treatment, if aggressive or conservative ${ }^{4}$.

In the present study the suspected diagnosis of ovarian torsion was based on the clinical picture of lower abdominal pain and endovaginal sonography 
showed the classical picture of ovarian torsion such as, ovarian enlargement with fluid in the cul-de-sac and few cases showing whirlpool sign. Colour Doppler showed reduction of arterial flow and absence of venous flow to the affected ovary. Present study showed that early diagnosis based on clinical parameters and high index of suspicion could help the ovarian conservation in young women and laparoscopic detorsion could be safely performed in the majority of patients. The advantage of laparoscopic surgery are well established. Strict case selection is necessary to exclude malignant tumours which should be treated by conventional surgery.

\section{References}

1. Mancuso A, Broccio G, Augo LG, Pirri V. Adnexal torsion in pregnancy. Acta Obstet Gynecol Scand 1997; 76: 83-4. URL: http://www.ncbi.nlm.nih.gov/pubmed/9033251

2. Schraga E. Ovarian torsion. eMedicine Specialties, Emergency Medicine, Obstetrics and Gynaecology, 2009.

URL: http://emedicine.medscape.com/article/795994overview

3. Tadulwadkar S, Shah A, Agarwal B. Detorsion and conservative therapy for twisted adnexa: our experience. Journal of Gyneological Endoscopy and Surgery 2009; 1: 21-25.

URL: http://www.gynecendoscopy.org/article.asp?issn= 0974-1216; year=2009; volume=1;issue =1; page=21; epage =26; aulast $=$ Tandulwadkar

4. Sebastiao M, Zanforlin Filho, Edward et al. Diagnosis of ovarian torsion by three dimensional Power Doppler in first trimester of pregnancy. Journal of Obstetrics and Gynaecology Research 2008; 34: 266-70.

URL: http://zariba.ingenta.com/content/bsc/jog/2008/ $00000034 / 00000002 /$ art00024;jsessionid $=15$ cxlpw52 w9r.alice
5. Maschiah S, Goldenberg M, Bilder D, Ben-Pafael Z, Moran O. Adnexal torsion in hyperstimulated ovaries in pregnancies after gonadotrophin therapy. Fertility Sterility 1996; 53: 76-80.

URL: http://www.ncbi.nlm.nih.gov/pubmed/2295348

6. Albayram F, Hamper UM. Ovarian and adnexal torsion: spectrum of sonographic findings with pathologic correlation. J Ultrasound Med 2001; 20: 1083-9.

URL: http://www.ncbi.nlm.nih.gov/pubmed/11587015? tool=bestpractice.bmj.com

7. Schultz LR, Newton WA, Clatworthy HW. Torsion of previously normal tube and ovary in children. NEngl J Med 1963; 268: 343-6.

URL: http://www.nejm.org/doi/pdf/10.1056/NEJM 196302142680703

8. Coleman BG. Transvaginal sonography of adnexal masses. Radiol Clin North A 1992; 30: 677-91.

URL: http://www.ophsource.org/periodicals/ophtha/ medline/record/MDLN.1631277

9. Rha SE, Byun JY, Jung SE, et al. CT and MR imaging features of adnexal torsion. Radiographics 2002; 22: 283-94.

URL: http://radiographics.rsna.org/content/22/2/283. abstract

10. Warner MA, Fleischer AC, Edell SL, et al. Uterine adnexal torsion: sonographic findings. Radiology 1985; 154: 773-5.

URL: http://radiology.rsna.org/content/154/3/773. abstract

11. Graif M, Shalov J, Strauss S, Engelberg S, Mshiach S, Itzchak Y. Torsion of the ovary: sonographic features. Am J Roentgenol 1984; 143: 1331-4.

URL: http://www.ajronline.org/cgi/content/abstract/ $143 / 6 / 1331$ 